04.1

\title{
Параметры высоковольтных разрядов на лопастях винтов вертолета и создаваемых ими электромагнитных помех
}

\author{
() М.Е. Гущин, И.Ю. Зудин, С.В. Коробков, А.В. Костров, П.А. Микрюков, С.Э. Привер, \\ А.В. Стриковский, В.С. Сысоев
}

Федеральный исследовательский центр Институт прикладной физики РАН, Нижний Новгород, Россия
E-mail: mguschin@ipfran.ru

Поступило в Редакцию 8 октября 2019г.

В окончательной редакции 8 октября 2019г.

Принято к публикации 14 октября 2019г.

\begin{abstract}
Исследованы параметры импульсного разряда, возникающего между электрически изолированными металлическими деталями лопастей вертолетов и создающего помехи для бортовых радиостанций в диапазоне коротких и ультракоротких волн. Причиной возникновения разряда является дифференциальная электризация вертолета в полете. В натурных и лабораторных экспериментах установлены диапазоны разрядных напряжений и токов, а также амплитудные и спектральные характеристики радиопомех, наводимых этими разрядами на бортовые антенны.
\end{abstract}

Ключевые слова: электризация летательных аппаратов, стримерный разряд, радиоизлучение, антенна.

DOI: 10.21883/PJTF.2020.02.48946.18063

Известно, что корпус летательного аппарата (ЛА) в полете может приобретать высокий электрический потенциал за счет внешней [1] либо внутренней (двигательной) [2,3] электризации. Если ЛА цельнометаллический, то все его части оказываются под одинаковым (пусть и высоким) потенциалом относительно земли, и разряда между деталями не происходит. Если же во внешней конструкции ЛА используются диэлектрические материалы, то возрастает вероятность возникновения разряда между близкорасположенными металлическими деталями, не имеющими надежного контакта между собой и с корпусом [4].

В настоящее время многие детали лопастей несущих и рулевых винтов вертолетов изготавливаются из диэлектрических композитов. При этом необходимость защиты лопастей от износа требует их усиления абразивостойкими профилями [5], состоящими из отдельных металлических элементов (оковок). Фактически на диэлектрической основе лопасти размещается до нескольких десятков металлических деталей площадью порядка $100 \mathrm{~cm}^{2}$ каждая, разделенных малыми промежутками. Поэтому лопасти винтов являются одними из наиболее „опасных“ узлов современного вертолета с точки зрения возникновения электростатического разряда. Ранее наряду с измерениями потенциала корпуса вертолета в полете [6] нами было установлено, что именно на винтах находятся основные источники импульсных радиопомех в диапазоне коротких и ультракоротких волн (КВ и УКВ). При разряде потенциалы металлических деталей, разделенных диэлектрическими зазорами, выравниваются, однако за счет продолжающейся электризации спустя некоторое время происходит следующий разряд. После детектирования в речевом канале радиостанции помеха имеет характер треска.

Для нейтрализации помех необходимо не только определить место возникновения разрядов, но и знать их количественные характеристики. Провести синхронные измерения параметров разрядов и вызываемых ими радиопомех на борту вертолета в полете очень сложно. Что касается наземных измерений, то в отсутствие естественной электризации вертолета они требуют использования высоковольтной испытательной техники. Подача высокого напряжения на реальный вертолет представляет угрозу для дорогостоящего оборудования и небезопасна. Поэтому для получения количественной информации о параметрах разряда и помех от него нами была использована методика, включавшая в себя, с одной стороны, пассивные измерения на борту вертолета в полете, а с другой - лабораторное исследование высоковольтных разрядов на отдельных деталях вертолета. Отметим, что свойства источника помехи напрямую зависят от фактического пути протекания тока через металлические детали лопасти и разрядные промежутки между ними, т.е. исследования с использованием оригинальных деталей вертолета являются обязательным этапом работы.

Измерения помех в полете выполнялись с помощью анализатора спектра FSH-4, подключаемого на вход штатной УКВ-антенны, расстояние от которой до несущего винта вертолета составляло около $1 \mathrm{~m}$. Независимым источником информации о помехах служили зашумленные записи переговоров экипажа в речевом канале, которые позволяли оценивать период следования импульсов помехи и ее интенсивность. При высоковольтных лабораторных испытаниях лопастей между их металлическими деталями прикладывалось постоянное напряжение величиной до $20 \mathrm{kV}$. Импульсный ток в разрядной цепи измерялся с помощью пояса Роговского, помехи на различных расстояниях от лопасти регистрировались экранированной рамочной антенной. Наконец, для получения однозначной связи характеристик сигналов, регистрируемых рамочной антенной и бортовой 


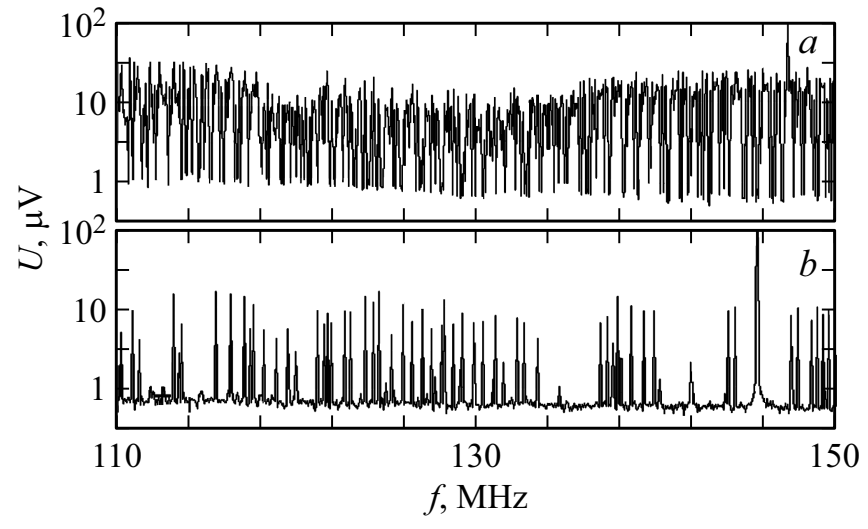

Рис. 1. Спектральные записи помех, наводимых на УКВ-антенну вертолета в полете. $a-$ интенсивная радиопомеха, $b$ - менее интенсивная помеха в форме последовательности неперекрывающихся (одиночных) импульсов.

антенной вертолета, были проведены калибровочные эксперименты с имитатором помехи - разрядником с миллиметровым межэлектродным зазором, включавшимся при тех же значениях напряжения, при которых происходит пробой на лопастях винтов. В этих исследованиях штатная УКВ-антенна на технологическом имитаторе фюзеляжа вертолета и рамочная антенна устанавливались на одном расстоянии от разрядника. Сигналы с датчиков и антенн подводились коаксиальными кабелями на входы широкополосных цифровых осциллографов с согласованными входными сопротивлениями $(50 \Omega)$.

Записи радиопомех в тракте УКВ-антенны вертолета приведены на рис. 1. Интервалы между импульсами помехи (1-10 ms) существенно короче, чем период качания частоты в диапазоне анализа, составляющий в данном случае $T_{0}=2 \mathrm{~s}$. При выбранной полосе входного фильтра анализатора и видеодетектора $(\Delta f=10 \mathrm{kHz})$ помеха выглядит на спектральной развертке как всплески, соответствующие разрядным импульсам. Время усреднения анализатора $T_{0} / N=3 \mathrm{~ms}$, где $N=631$ количество точек развертки. У интенсивной помехи интервал между импульсами меньше $3 \mathrm{~ms}$ и разрешить отдельные импульсы помехи трудно (рис. 1, $a$ ). У помехи умеренной интенсивности интервалы между импульсами превышают время усреднения, и на спектральной развертке эти импульсы хорошо разрешаются (рис. 1,b). Среднеквадратичный уровень напряжения помехи около $10 \mu \mathrm{V}$.

При высоковольтных испытаниях, проводившихся в ангаре, штатная лопасть вертолета устанавливалась на деревянных ложементах (изоляторах) на уровне около $1 \mathrm{~m}$ от пола. Абразивостойкий профиль лопасти образован оковками, установленными с промежутками менее $1 \mathrm{~mm}$. Внутри диэлектрической лопасти находятся металлические детали, электрически соединяемые с корпусом вертолета, некоторые из которых отделены от оковок диэлектрической прослойкой толщиной по- рядка $1 \mathrm{~mm}$, например пластины нагревателей противообледенительной системы. Испытания показали, что промежуток между соседними оковками пробивается при напряжении до $1.5 \mathrm{kV}$. Пробой двух промежутков через одну оковку происходит приблизительно при $3 \mathrm{kV}$; при том же напряжении пробивается слой диэлектрика между оковками и пластинами противообледенительной системы. Напряжением 6-7kV пробивается весь ряд оковок лопасти (рис. 2). Свойства разрядов при подаче высокого напряжения между оковками, а также между оковками и внутренними металлическими деталями лопасти достаточно близки. Полная длительность каждого разряда, представляющего собой затухающие колебания тока с пиковой амплитудой в несколько ампер, составляет величину около $1 \mu \mathrm{s}$ (рис. 3,a). Разряды между внешними металлическими деталями лопасти выглядят как тонкие каналы с голубоватым свечением. Перечисленные свойства позволяют идентифицировать разряд на лопасти как стримерный разряд.

Размещая антенну на различных расстояниях от лопасти, можно имитировать взаимное расположение лопастей винта и элементов радиооборудования на фюзеляже вертолета. Типичная форма одиночного импульса радиопомехи, регистрируемого рамочной антенной, и его частотный спектр показаны на рис. 3, b,c. Имея максимум при $f_{\text {max }} \sim 10 \mathrm{MHz}$, спектр импульса помехи простирается до частот $f_{0} \sim 400 \mathrm{MHz}$. Это согласуется с результатами численного моделирования спектра радиоизлучения стримерных разрядов [7]. Что касается амплитуды сигнала помехи, наводимого на штатную УКВ-антенну, то она по данным экспериментов с высоковольтным разрядником приблизительно в 50 раз превышает амплитуду сигнала с рамочной антенны, установленной на том же расстоянии. Таким образом, по рис. $3, b$ можно оценить максимальную амплитуду напряжения помехи, наводимого на УКВ-антенну вертолета, на уровне $1 \mathrm{~V}$.

Для дальнейших оценок используем следующие параметры импульсной радиопомехи на бортовой антенне: амплитуда напряжения $u_{0}=0.2-1 \mathrm{~V}$ в зависимости от расстояния до лопасти, длительность $\tau_{0}=250 \mathrm{~ns}$, ширина частотного спектра $\Delta F=25 \mathrm{MHz}$ (рис. $3, c$ ). Для

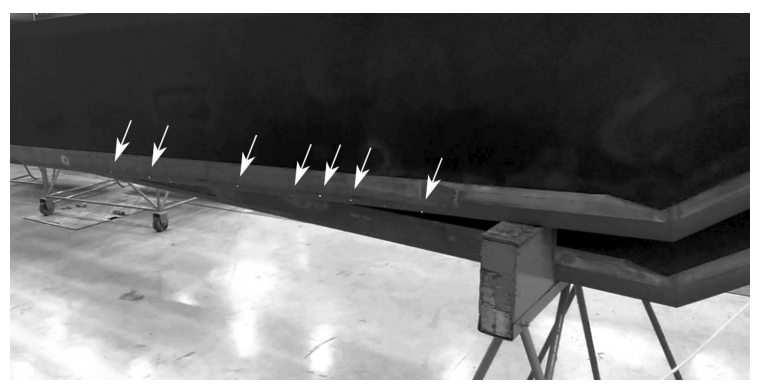

Рис. 2. Разряды (показаны стрелками), возникающие на промежутках между отдельными деталями абразивостойкого профиля лопасти несущего винта вертолета при подаче высокого напряжения. 

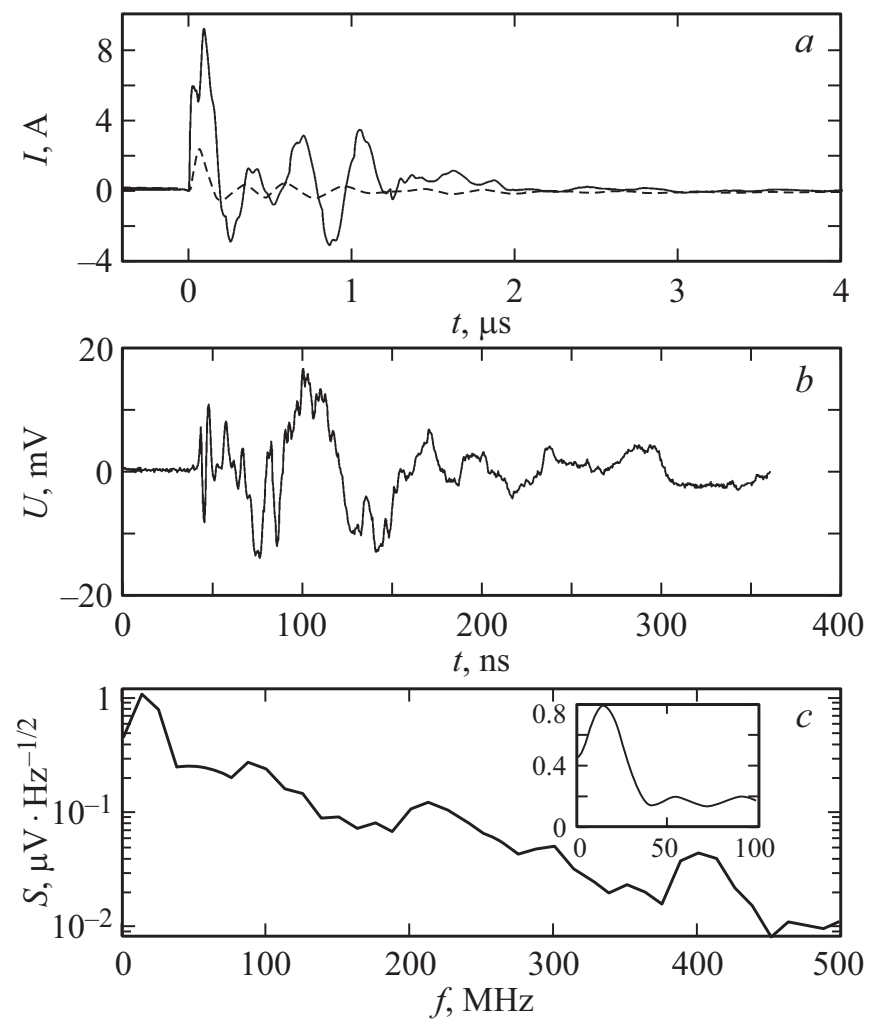

Рис. 3. Импульсные сигналы, полученные при лабораторных исследованиях на лопасти несущего винта вертолета. $a-$ осциллограммы разрядного тока на промежутках между металлическими деталями: сплошная кривая - между соседними оковками лопасти (напряжение $1.5 \mathrm{kV}$ ), штриховая - между оковкой и внутренней деталью лопасти (напряжение $3 \mathrm{kV}$ ); $b$ - типичная осциллограмма помехи, регистрируемой рамочной антенной на расстоянии $1 \mathrm{~m}$ от лопасти; $c$ - частотный спектр помехи (на вставке - спектр в области низких частот в линейном масштабе).

импульса конечной длительности квадрат спектральной плотности напряжения помехи в максимуме оценивается как $U^{2}\left(f_{\max }\right) \sim u_{0}^{2} \tau_{0} / \Delta F$. Далее, согласно данным рис. 3, $c$, отношение спектральной плотности помехи на частотах $f_{0} \sim 100 \mathrm{MHz}$ к максимальной спектральной плотности составляет $k=U\left(f_{0}\right) / U\left(f_{\max }\right) \sim 10^{-1}$. Для импульса помехи, приходящего в канал анализатора с большой постоянной времени $\left(\Delta f^{-1} \gg \tau_{0}\right)$, длительность импульса напряжения, наводимого на частоте $f_{0}$, оказывается порядка $\Delta f^{-1}$, а его амплитуда $-U\left(f_{0}\right) \Delta f$. С учетом времени усреднения анализатора среднеквадратичное напряжение на частоте $f_{0}$, наведенное одиночным импульсом помехи, оценивается следующим образом:

$$
u_{\mathrm{RMS}} \sim k u_{0}\left(\frac{N \tau_{0}}{T_{0}} \frac{\Delta f}{\Delta F}\right)^{1 / 2} \sim 6-30 \mu \mathrm{V}
$$

Этот результат соответствует бортовым измерениям (рис. 1). Следовательно, разряд, полученный на лопастях в лабораторных условиях, имеет те же параметры, что и разряд, развивающийся в результате электризации вертолета в полете.

Выполненные исследования позволяют сделать вывод о возможности изучения разрядных процессов на борту ЛА в лабораторных условиях методом имитационного моделирования. Лабораторные результаты достаточно хорошо согласуются с летными измерениями, что позволяет рассматривать их как основу для расчета и проектирования радиотехнических систем вертолета, функционирующих в условиях электризации и связанных с ней радиопомех. Разряды, развивающиеся на борту ЛА с диэлектрическими вставками в конструкции, в определенных погодных условиях создают достаточно мощные помехи в диапазонах КВ и УКВ, и для их нейтрализации необходимо принимать специальные меры.

\section{Благодарности}

Авторы выражают глубокую признательность Ю.П. Палочкину и сотрудникам предприятий холдинга „Вертолеты России“ за помощь в организации уникальных лабораторных и летных экспериментов.

\section{Финансирование работы}

Исследование поддержано Российским научным фондом (проект № 19-19-00501).

\section{Конфликт интересов}

Авторы заявляют, что у них нет конфликта интересов.

\section{Список литературы}

[1] Темников А.Г., Гилязов М.З., Матвеев Д.А., Воронкова А.Ю., Черненский Л.Л., Орлов А.В. // Письма в ЖТФ. 2011. T. 37. В. 18. C. 7-16.

[2] Нагель Ю.А. // ЖТФ. 1999. Т. 69. В. 8. С. 55-59.

[3] Sorokin A., Arnold F. // Atmospheric Environment. 2004. V. 38. N 7. P. 2611-2618.

[4] Ватажин А.Б., Голенцов Д.А., Лихтер В.А. // Изв. РАН. Механика жидкости и газа. 2006. № 5. С. 152-159.

[5] Дорошенко Н.И., Демидович Л.Н., Воробьев С.С., Сиротинский Б.С. Лопасть несущего винта вертолета. Патент РФ 2148532. Дата публикации: 10.05.2000. Заявка № 99106595/28 от 29.03.1999.

[6] Варфоломеев А.А., Гущин М.Е., Коробков С.В., Костров А.В., Палочкин Ю.П., Привер С.Э., Одзерихо Д.А., Стриковский А.В. // Письма в ЖТФ. 2015. Т. 41. В. 1. C. 28-35.

[7] Shi F., Liu N., Dwyer J.R., Ihaddadene K.M.A. // Geophys. Res. Lett. 2018. V. 46. N 1. P. 443-451. DOI: $10.1029 / 2018$ GL080309 